\title{
The Determination of the Rate of Deiodination of Thyroxine in Human Subjects *
}

\author{
M. Anbar, $†$ S. Guttmann, G. Rodan, and J. A. Stein \\ (From the Weizmann Institute of Science, Rehovoth, and the Hadassah Municipal Hospital, \\ Tel Aviv, (srael)
}

The importance of the peripheral degradation of thyroxine as a parameter of thyroid function has been emphasized in a number of investigations during the last decade (1-4). A correlation has been found between the rate of turnover of the hormone and the thyroid state, as determined by prevailing diagnostic methods. In these studies the rate of plasma disappearance was followed for about 2 weeks, and the biological half-life of thyroxine was determined by extrapolation techniques. The half-life of thyroxine- ${ }^{131} \mathrm{I}$ in the plasma of normal subjects ranged between 6 and 8 days, whereas in hyperthyroidism it was as short as 3 days. In hypothyroidism half-lives of about 10 days were observed. In a series of studies of the age dependent changes in thyroid function, a significant decrease of the rate of thyroxine turnover with age was observed in euthyroid subjects (4).

It is inherent in the methods of investigation employed in the studies cited that the rate of plasma disappearance of radiothyroxine is the combined result of all the degradative and excretory processes. Since deiodination is the major catabolic pathway of thyroxine, it was the purpose of this study to follow the kinetics of this process directly and solely.

The process of deiodination might be followed by determining the buildup of inorganic iodine originating from thyroxine. However, the great number of parameters that determine iodide me-

\footnotetext{
* Submitted for publication October 25, 1963; accepted August 19, 1965.

This study was supported by a research grant from the International Atomic Energy Agency, Vienna (contract $178 / \mathrm{RB}$ ), and it was carried out in the Laboratories of the Israel Atomic Energy Commission, Soreq Nuclear Research Center, Yavne, Israel.

$\dagger$ Address requests for reprints to Dr. M. Anbar, Isotope Dept., the Weizmann Institute of Science, Rehovoth, Israel.
}

tabolism in humans (thyroid and kidney removal, pool phenomena, and so on) (5) makes it impossible to estimate directly the rate of deiodination of thyroxine without far-reaching assumptions (6). To cope with this problem a double tracer method was devised, by which the rate of buildup of iodide that originates from labeled thyroxine is followed simultaneously with the aid of a different radioisotope of iodine. In an earlier attempt thyroxine- ${ }^{131} \mathrm{I}$ and iodide- ${ }^{132} \mathrm{I}$ were used (7), but the short physical half-life (2.3 hours) of ${ }^{132} \mathrm{I}$ was a major drawback that limited the usefulness of this method. In the present study ${ }^{125}$ I-labeled thyroxine and iodide- ${ }^{131} \mathrm{I}$ were used, and a group of euthyroid subjects was examined.

\section{Methods}

Materials. L-Thyroxine- ${ }^{225} \mathrm{I}$ labeled in the $3^{\prime}$ and $5^{\prime}$ positions was prepared by isotopic exchange (8) between purified $l$-thyroxine and carrier-free iodine ${ }^{125} .1$ The specific activity of the labeled thyroxine ranged between 30 and $\mathbf{4 0}$ mc per $\mathrm{mg}$. The radioactive thyroxine was tested before use by paper chromatography (solvent system, $n$-butanol: acetic acid: $\mathrm{H}_{2} \mathrm{O}=78: 10: 50$; butanol:ethanol:ammonia $=5: 1: 2$ ), and 95 to $98 \%$ of the radioactivity was that of thyroxine, the major impurity being iodide.

The iodide-131 I used was carrier-free sterilized solution in normal saline. ${ }^{2}$

Method of examination. L-Thyroxine labeled with io$\operatorname{dine}^{125}$ (50 $\mu \mathrm{c}$ in $50 \%$ propylene glycol solution) was injected intravenously into the subjects examined, 48 hours before an injection of iodide ${ }^{131}$. During this period complete equilibration of the thyroxine within its space of distribution was attained, whereas any labeled impurities were excreted. On the day of the test $10 \mu \mathrm{c}$ of carrier-free iodide $^{131}$ was injected intravenously, and urine and blood samples were collected simultaneously at 4,6 , and 8 hours after the injection. During the test, subjects continued their daily routines.

\footnotetext{
${ }^{1}$ Obtained from Nuclear Science and Engineering Co., Pittsburgh, Pa.

2 Obtained from the Radiochemical Centre, Amersham, England.
} 
To portions of the urine samples a few grains of an anion exchange resin ${ }^{3}$ were added to absorb the iodide and thereby to attain better geometrical conditions for counting. The presence of ion exchange resin at the bottom of the tube permitted more efficient and reproducible counting in the well counter. The radioactivity of the samples was determined in thin walled cellulose nitrate test tubes to minimize the adsorption of the low energy gamma radiation of iodine ${ }^{125}$.

The radioactivities of ${ }^{125} \mathrm{I}$ and ${ }^{131} \mathrm{I}$ were determined simultaneously in a well-type $\mathrm{NaI}$ scintillation detector equipped with two single channel pulse height analyzers and two scalers. One analyzer was set with a channel between 20 and $40 \mathrm{Kev}$ (channel $A$ to count ${ }^{125} \mathrm{I}$ ), and the other was set between 100 and $400 \mathrm{Kev}$ (channel B to count ${ }^{131}$ I only). To determine the contribution in channel A due to ${ }^{131} \mathrm{I}$ a standard sample of ${ }^{131}$ I was measured, and the ratio $(R)$ of count rates of ${ }^{131}$ I was calculated,

$$
\mathrm{R}=\frac{\left({ }^{131} \mathrm{I} \text { counts per minute) in channel } \mathrm{A}\right.}{\left({ }^{131} \mathrm{I} \text { counts per minute) in channel } \mathrm{B}\right.}
$$

The instruments were set to obtain a ratio of 0.05 or less. From the count rates in both channels the corresponding net count rates of ${ }^{131} \mathrm{I}$ and ${ }^{125}$ I were calculated. The count rate of ${ }^{131} I\left(C_{B}\right)$ was obtained directly from channel $B$. The count rate of ${ }^{125} \mathrm{I}$ was calculated by subtracting the fractional contribution of ${ }^{131} I\left(C_{B} R\right)$ from the total count rate in channel $A\left(C_{A}\right)$,

$$
\text { counts per minute }{ }^{125} \mathrm{I}=\mathrm{C}_{\mathrm{A}}-\mathrm{C}_{\mathrm{B}} \mathrm{R} \text {. }
$$

Calculation of the rate of deiodination. The composite rate of degradation of thyroxine may be expressed by

$$
-\mathrm{dT}_{4} / \mathrm{dt}=\mathrm{k}_{\mathrm{d}} \mathrm{T}_{4}+\mathrm{k}_{\mathrm{a}} \mathrm{T}_{4},
$$

where $T_{4}$ is the labeled thyroxine, $k_{d}$ is the velocity constant of deiodination of thyroxine, and $\mathrm{k}_{\mathrm{a}}$ is the corresponding constant for other degradative and excretory processes. The constant $k_{d}$ may be calculated by measuring the iodide $\left(\mathrm{I}^{-}\right)$originating from the labeled thyroxine in the organism, whose concentration in the plasma depends on the rate of deiodination of thyroxine and the rate of iodide removal. This may be expressed by

$$
\mathrm{dI}^{-} / \mathrm{dt}=\mathrm{k}_{\mathrm{d}} \mathrm{T}_{4}-\mathrm{k}_{\mathrm{c}} \mathrm{I}^{-},
$$

where $k_{c}$ is the velocity constant of iodide removal from the plasma (renal, thyroidal, and other). In humans iodide is removed 70 times faster than it is formed (5), and the rate of change of iodide in the plasma, therefore, is close to zero. Hence, Equation 4 can be written as,

$$
\mathrm{k}_{\mathrm{d}}=\mathrm{k}_{\mathrm{c}}\left(\mathrm{I}^{-} / \mathrm{T}_{4}\right) \text {. }
$$

The rate of deiodination can thus be evaluated from the rate of iodide removal $\left(\mathrm{k}_{\mathrm{c}}\right)$ and the steady state concentration of iodide originating from the labeled thyroxine $\left(\mathrm{I}^{-} / \mathrm{T}_{4}\right)$. Owing to the fact that the labeled iodide originating from thyroxine is of the order of 1 to $2 \%$ of the total labeled iodine content in the plasma, it is impossible to determine its value with sufficient accuracy. On the other hand,

\footnotetext{
${ }^{3}$ Dowex 1-X 10, Dow Chemical Co., Midland, Mich.
}

iodide is selectively excreted by the kidneys, and under conditions of normal renal function no protein-bound iodine is excreted in the urine. When iodide- ${ }^{131} \mathrm{I}$ is administered and is allowed to equilibrate with iodide--125I, which originates from the deiodination of thyroxine-125I, both radioisotopes will be excreted in the urine at a rate proportional to their relative concentrations in the plasma. This makes it possible to calculate the concentrations of iodide-125I in the plasma $\left.{ }^{125} I_{P}\right)$,

$$
\frac{{ }^{131} I_{U}}{{ }^{125} I_{U}}=\frac{{ }^{131} I_{P}}{{ }^{125} I_{P}} \text { or }{ }^{125} I_{P}=\frac{131 I_{P} \times{ }^{125} I_{U}}{{ }^{131} I_{U}},
$$

where $I_{U}$ and $I_{P}$ are the concentrations of iodide radioisotopes in urine and plasma, respectively. The radioactivity in urine, ${ }^{131} I_{U}$ and ${ }^{125} I_{U}$, represents inorganic iodide only, except in proteinuria, where the protein-bound fraction may be separated.

The plasma radioactivity of ${ }^{125} \mathrm{I}$ is at least $98 \%$ that of thyroxine; thus, at first approximation, it is equal to that of protein-bound iodine ( $\mathrm{PBI}{ }^{125}$ ).

The activity of iodide- ${ }^{131} \mathrm{I}$ in the plasma, ${ }^{131} \mathrm{I}_{\mathrm{P}}$, is determined after separation of the plasma protein-bound iodine (PBI) by the usual techniques. In eu- and hypothyroid subjects the ${ }^{131}$ I plasma radioactivity is at least $95 \%$ iodide during the period of examination ( 8 hours). It is thus a measure of ${ }^{131} I_{P}$ and does not necessitate PBI separation. Subjects with a high conversion ratio obviously require PBI separation.

If we substitute into Equation 5,

$$
\mathrm{k}_{\mathrm{d}}=\mathrm{k}_{\mathrm{o}} \frac{{ }^{131} \mathrm{I}_{\mathrm{P}} \times{ }^{125} \mathrm{I}_{\mathrm{U}}}{{ }^{131} \mathrm{I}_{\mathrm{U}} \times \mathrm{PBI}^{125}}
$$

The value of $k_{c}$ (the rate of plasma disappearance of iodide) is calculated from Equation 8,

$$
\mathrm{d}\left({ }^{131} I_{P}\right) / d t=k_{c} t
$$

which on integration yields,

$$
\ln \left({ }^{131} I_{P}\right)_{t_{2}} /\left({ }^{131} I_{P}\right)_{t_{2}}=k_{c}\left(t_{2}-t_{1}\right),
$$

where the indices refer to the beginning and the end of a time interval.

The above equation may also be written,

$$
\mathrm{k}_{\mathrm{o}}=(2.303 / \Delta \mathrm{t})\left[\log \left({ }^{131} \mathrm{I}_{\mathrm{P}}\right)_{\mathrm{t}_{1}} /\left({ }^{131} \mathrm{I}_{\mathrm{P}}\right)_{\mathrm{t}_{2}}\right],
$$

with $t_{2}-t_{1}=\Delta t$, expressed in hours.

The final formula for $\mathbf{k}_{\mathbf{d}}$ may then be derived from Equations 5,6 , and 10 ,

$$
\begin{aligned}
\mathrm{k}_{\mathrm{d}}=(1 / \Delta \mathrm{t}) \times \frac{1}{2} \times\left[\left({ }^{125} \mathrm{I}_{\mathrm{U}} /{ }^{131} \mathrm{I}_{\mathrm{U}} \times{ }^{131} \mathrm{I}_{\mathrm{P}} / \mathrm{PBI}{ }^{125}\right)_{\mathrm{t}_{1}}\right. \\
\left.+\left({ }^{125} \mathrm{I}_{\mathrm{U}} /{ }^{131} \mathrm{I}_{\mathrm{U}} \times{ }^{131} \mathrm{I}_{\mathrm{P}} / \mathrm{PBI}^{125}\right)_{\mathrm{t}_{2}}\right] \\
\times 2.3\left[\log \left({ }^{131} \mathrm{I}_{\mathrm{P}}\right)_{\mathrm{t}_{1}} /\left({ }^{131} \mathrm{I}_{\mathrm{P}}\right)_{\mathrm{t}_{2}}\right] .
\end{aligned}
$$

The specific rate constant of deiodination, $k_{d}$, for an interval $\Delta t$ is then calculated by substituting the mean values of plasma and urine radioactivities at the beginning and the end of the time interval.

The half-time of deiodination in days may be then calculated,

$$
t_{i}(\text { days })=\frac{0.693}{k_{d} \times 24} .
$$




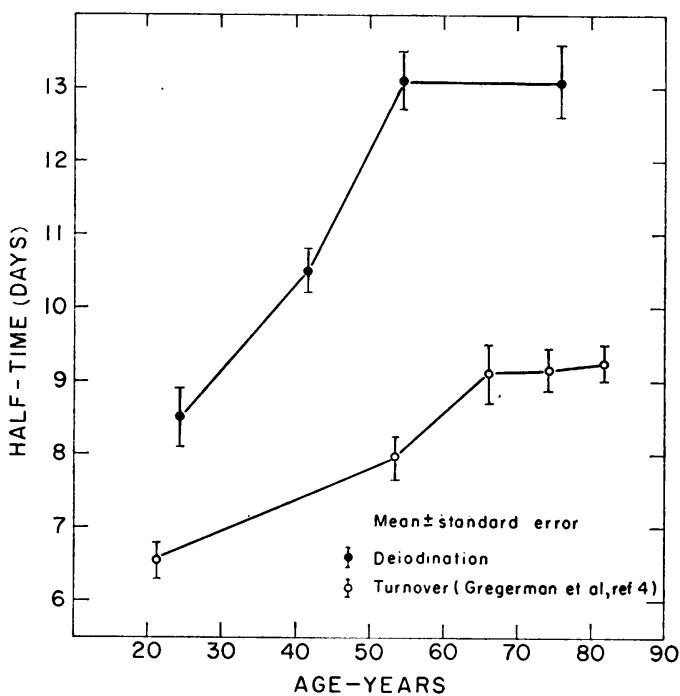

Fig. 1. THE EFFect OF AGE ON THE RATE OF DEIODINATION AND TURNOVER OF THYROXINE IN EUTHYROID SUBJECTS.

\section{Results}

The rate of deiodination of thyroxine was determined in 165 euthyroid subjects, male and female, who were in good health. The age range was between 18 and 86 . The rates of deiodination in male and female subjects of the same age group were comparable; the results are therefore presented without specifying sex.

The analysis of the data obtained reveals an agedependent change in the rate of deiodination. Figure 1 and Table I demonstrate the relationship of thyroxine deiodination to age. The change in the half-time of deiodination with age is linear and highly significant between the ages 18 and $60(\mathrm{r}=$ $+0.71, \mathrm{p}<0.01)$. Somewhat lower significance in the coefficient of correlations is obtained when the age group over 60 is also included ( $r=$ $+0.60, p<0.01)$. From the mean values of the different age groups presented in Table I, it can

TABLE I

Mean half-time values of the rate of deiodination of thyroxine

\begin{tabular}{crcc}
\hline \hline Mean age & Age range & $\begin{array}{c}\text { Number } \\
\text { of subjects }\end{array}$ & Deiodination, $\mathrm{t}_{\mathbf{s}}$ \\
\hline \multicolumn{4}{c}{ years } \\
24.7 & $18-33$ & 60 & days $\pm S D$ \\
41.7 & $34-50$ & 58 & $10.5 \pm 3.1$ \\
54 & $51-57$ & 36 & $13.1 \pm 2.7$ \\
74.6 & $62-85$ & 11 & $13.1 \pm 2.2$ \\
\hline
\end{tabular}

be seen that there is an increase in the half-time of deiodination from 8.5 days in the third decade to 13.1 days in the sixth decade, beyond which no significant increase is observed. Such an age dependence was already demonstrated by Gregerman, Gaffney, and Shock (4), when the total turnover of thyroxine was studied. On the other hand, no significant differences in the 24-hour ${ }^{131}$ I uptake in the thyroid gland were observed over the whole age range, in agreement with the results of previous studies (9).

To estimate the share of deiodination in the total thyroxine turnover, a comparison was made between the results of Gregerman and co-workers (4) and ours. From the calculated values of rates of deiodination and the over-all turnover (Table II), it may be seen that the excretory pathways

TABLE II

Calculated values of the rate of thyroxine excretion in different ages*

\begin{tabular}{lccc}
\hline \hline Decade & $\begin{array}{c}\text { Rate of } \\
\text { deiodination } \\
\left(\mathbf{k}_{\mathbf{d}} \text { day }^{-1}\right) \dagger\end{array}$ & $\begin{array}{c}\text { Rate of } \\
\text { turnover } \\
\left(\mathbf{k}_{\mathrm{t}} \text { day }^{-1}\right)\end{array}$ & $\begin{array}{c}\text { Rate of } \\
\text { excretion } \\
\left(\mathbf{k}_{\mathrm{t}}-\mathbf{k}_{\mathbf{d}}\right. \\
\left.\mathbf{k}_{\text {excretion }}\right)\end{array}$ \\
\hline 2 & 0.083 & 0.105 & 0.022 \\
3 & 0.071 & 0.096 & 0.025 \\
4 & 0.062 & 0.091 & 0.029 \\
5 & 0.053 & 0.085 & 0.032 \\
6 and above & 0.053 & 0.075 & 0.022
\end{tabular}

* Calculated from Table I and from the results of Gregerman and co-workers in Reference 4.

$\dagger k_{d}=$ velocity constant for deiodination of thyroxine.

of thyroxine, which are mainly fecal, increase slightly with age. It may also be shown that the contribution of deiodination to the over-all turnover decreases somewhat with age (Figure 1). In the low and medium age groups deiodination accounts for about $80 \%$ of the over-all rate, and it decreases to about $70 \%$ in the advanced ages. It may be concluded that the major parameter in the degradation of thyroxine that changes with age is its deiodination.

The rate of deiodination in different cases of thyroid disorders has been determined in order to evaluate the potential diagnostic use of the double tracer method. The results presented in Table III show conspicuous differences between hypoand hyperthyroid cases, which differ in their rate of deiodination by a factor of 5. Propylthiouracil (PTU) was shown to decrease the rate of deiodination by a factor of 2 , in agreement with results 
TABLE III

The half-time of deiodination of thyroxine in thyroidal disorders

\begin{tabular}{cccccc}
\hline \hline No. & Patient & Age & $\begin{array}{c}\text { 24-hour 121 } \\
\text { uptake }\end{array}$ & $\mathrm{t}_{3}$ & Notes \\
\hline 1 & S.A. & years & $\begin{array}{l}\% \\
\text { days }\end{array}$ & Hyperthyroidism \\
2 & K.R. & 50 & 56 & 6.1 & Hyperthyroidism \\
3 & F.H. & 50 & 47 & 6.2 & Hyperthyroidism \\
4 & F.A. & 54 & 2.0 & 18.5 & Hypothyroidism \\
5 & P.S. & 40 & 7.2 & 21.2 & $\begin{array}{c}\text { Hypothyroidism } \\
6\end{array}$ \\
Z.B. & 75 & 94 & 28.6 & $\begin{array}{c}\text { Toxic adenomatous goiter } \\
\text { 6 weeks under PTU* treatment }\end{array}$ \\
7 & J.C. & 47 & 2.1 & 16.2 & $\begin{array}{c}\text { Normal subject receiving } \\
\text { PTU 7 days }\end{array}$ \\
8 & H.A. & 58 & $<1$ & 9.2 & $\begin{array}{c}\text { Postthyroidectomy with } \\
\text { thyroidin (100 mg per day) } \\
\text { replacement }\end{array}$ \\
\hline
\end{tabular}

* PTU = propylthiouracil.

obtained in humans and experimental animals $(10,11)$.

\section{Discussion}

It is well known that the major catabolism of thyroxine is its deiodination; however, the direct in vivo determination of this process in humans has not yet been carried out. In the investigations that dealt with the in vivo metabolism of thyroxine, the disappearance of radioactive thyroxine from the plasma was followed, and the values of halflives obtained represent both the degradation and the excretion patterns of the hormone. The routine determination of thyroxine turnover $(3,4$, 12) applies the extrapolation of plasma radioactivity to zero time. Ingbar and Freinkel (2) attempted to estimate the rate of peripheral or "cellular" metabolization of thyroxine by collecting data over a period of 10 to 16 days from daily plasma and urine and fecal samples, as well as thyroidal iodine uptake determinations. The double tracer method employed in the present study determines the rate of deiodination solely without using extrapolation techniques.

Considering the slow turnover of thyroxine, the examination by the present method is a short term determination. The method is independent of pool size estimates by dilution analysis, which are a well known source of inaccuracy in tracer methodology. The assay of the stable protein-bound iodine in the serum, which has been used as a parameter in the calculations of previous degradation studies, is another possible source of error. In the present method, the calculation of the rate of deiodination does not require the value of serum PBI. The difficulties and errors in excreta collection are also omitted, as all calculations are based on the ratios between the two iodide radioactive isotopes. This ratio can be determined in any volume, assuming that the metabolic fate of all iodine isotopes is identical.

The optimal period of the examination is about 8 hours. The first 4 hours are required for equilibration of iodide-131 I with the circulating iodide${ }^{125} \mathrm{I}$. The following 4-hour period allows an accurate estimate of the rate of iodide plasma disappearance. When the rate of thyroidal iodine conversion is high or in proteinuria, or both, the halflife of deiodination appears shortened; however, these conditions are easily detected, and errors resulting from them are readily avoided.

By using this method of examination in a group of euthyroid subjects (female and male), the halflife of deiodination of thyroxine was found to increase with age from 8 to 13 days. This small variability observed (Table I) is due to the fact that the present method is free of concentration parameters that are affected by nutritional factors. An analogous age dependence has been previously demonstrated by Gregerman and co-workers when 
they examined the over-all turnover of thyroxine. A quantitative comparison between the data of these authors and our data reveals, however, that the half-life of thyroxine deiodination increases with age to a greater extent than the over-all turnover.

The correlation between thyroidal states and rates of deiodination of thyroxine (Table III) suggests that the changes in the rate of deiodination are another manifestation of thyroidal disorder. This may perhaps be correlated with the availability of "free" thyroxine to the deiodinating sites. Such a correlation has been previously suggested by Gregerman and co-workers (4) to explain the age dependence of thyroxine turnover. The age dependence in the uptake of triiodothyronine by erythrocytes (13) supports this suggestion. The availability of a direct method for the determination of the rate of deiodination of thyroxine described in this study and the possibility of an estimate of the free hormone may facilitate a quantitative investigation of this correlation.

\section{Summary}

1) A method has been elaborated that determines the rate of deiodination of thyroxine in humans. The procedure is based on a double tracer technique, in which $l$-thyroxine- ${ }^{125} \mathrm{I}$ and iodide- ${ }^{131} \mathrm{I}$ are used simultaneously to determine the metabolic fate of the hormone. The examination takes 8 hours.

2) The rate of deiodination of thyroxine was determined in 165 euthyroid subjects, female and male.

3) A correlation between the half-time of the deiodination of thyroxine and age was found; the $t_{1}$ increases from 8 days in the third decade to 13 days in the sixth.

4) The half-time of thyroxine deiodination is affected by the thyroidal status. It is increased by a factor of 3 to 4 in hypothyroidism, whereas in hyperthyroidism it is decreased.

\section{Acknowledgments}

We wish to express our thanks to the volunteers of the settlements Massuot Yizhaq, En Zurim, and Shefayim, and of the Parents' Home, Kiryat Moshe, and to their physicians in charge, Drs. W. Cohn, E. K. Frenkel, and I. Yedwab for cooperation and encouragement.

\section{Appendix \\ Sample calculations}

1) The following data were obtained and are expressed as the mean counts per minute of duplicate determinations and corrected for ${ }^{131}$ I contribution to ${ }^{125}$ I counts.

TABLE AI Net counts per minute

\begin{tabular}{rrrrrr}
\hline & \multicolumn{2}{c}{${ }^{125} \mathrm{I}$} & & \multicolumn{2}{c}{${ }^{131 \mathrm{I}}$} \\
\cline { 2 - 3 } \cline { 5 - 6 } & Plasma & Urine & & Plasma & Urine \\
\hline$t_{1}$ & 980 & 3,088 & & 461 & 57,100 \\
$t_{2}$ & 1,040 & 2,300 & & 339 & 32,600 \\
$t_{3}$ & 955 & 2,842 & & 245 & 29,000 \\
\hline
\end{tabular}

$\left(t_{2}-t_{1}\right)=(\Delta t)_{1}=2.75 \quad$ hours; $\quad\left(t_{3}-t_{2}\right)=(\Delta t)_{2}$ $=2.80$ hours.

2). Substitution into Equation 11 (see text) yields the following:

$$
\begin{aligned}
\mathrm{k}_{\mathrm{d}_{1}}=\frac{1}{2.75} \times \frac{1}{2}\left[\left(\frac{3,088}{57,100} \times \frac{461}{980}\right)\right. & \\
\left.+\left(\frac{2,300}{32,000} \times \frac{339}{1,040}\right)\right] \times & 2.3 \log \frac{461}{339} \\
& =2.78 \times 10^{-3} \text { hour }^{-1},
\end{aligned}
$$

$\mathrm{k}_{\mathrm{d}_{2}}=\frac{1}{2.80} \times \frac{1}{2}\left[\left(\frac{2,300}{32,000} \times \frac{339}{1,040}\right)\right.$

$$
\begin{aligned}
\left.+\left(\frac{2,842}{29,000} \times \frac{245}{955}\right)\right] \times & 2.3 \log \frac{339}{246} \\
& =2.65 \times 10^{-3} \text { hour }^{-1} .
\end{aligned}
$$

Hence, the specific rate constant of deiodination, $k_{d}$, $=2.71 \times 10^{-3}$ hour $^{-1}$, and

$$
t_{i}=\frac{0.693}{0.00271}=255.7 \text { hours or } 10.6 \text { days. }
$$

\section{References}

1. Sterling, K., J. C. Lashof, and E. B. Man. Disappearance from serum of $I^{191}$-labeled $L$-thyroxine and L-triidothyronine in euthyroid subjects. J. clin. Invest. 1954, 33, 1031.

2. Ingbar, S. H., and N. Freinkel. Simultaneous estimation of rates of thyroxine degradation and thyroid hormone synthesis. J. clin. Invest. 1955, 34, 808.

3. Sterling, K., and R. B. Chodos. Radiothyroxine turnover studies in myxedema, thyrotoxicosis, and hypermetabolism without endocrine disease. J. clin. Invest. 1956, 35, 806.

4. Gregerman, R. I., G. W. Gaffney, and N. W. Shock. Thyroxine turnover in euthyroid man with special reference to changes with age. J. clin. Invest. 1962, 41, 2056. 
5. Riggs, D. S. Quantitative aspects of iodine metabolism in man. Pharmacol. Rev. 1952, 4, 284.

6. Ingbar, S. H., and N. Freinkel. Regulation of the peripheral metabolism of thyroid hormones. Recent Progr. Hormone Res. 1960, 16, 353.

7. Anbar, M. Application of iodine-132 in studies of thyroxine turnover in Production and Use of Shortlived Radioisotopes from Reactors. Vienna, International Atomic Energy Agency, 1963, vol. 2, p. 147.

8. Anbar, M., and S. Guttmann. In preparation.

9. Gaffney, G. W., R. I. Gregerman, and N. W. Shock. Relationships of age to the thyroidal accumulation, renal excretion and distribution of radioiodide in euthyroid man. J. clin. Endocr. 1962, 22, 784.
10. Slingerland, D. W., and B. A. Burrows. Inhibition by propylthiouracil of the peripheral metabolism of radiothyroxine. J. clin. Endocr. 1962, 22, 511.

11. Escobar del Rey, F., and G. Morreale de Escobar. The effect of propylthiouracil, methylthiouracil and thiouracil on the peripheral metabolism of L-thyroxine in thyroidectomized, L-thyroxine maintained rats. Endocrinology 1961, 69, 456.

12. Woeber, K. A., and S. H. Ingbar. The effects of noncalorigenic congeners of salicylate on the peripheral metabolism of thyroxine. J. clin. Invest. 1964, 43, 931.

13. Soltz, W. B., A. Horonick, and B. F. Chow. Agewise difference in the uptake of radioactive triiodothyronine $\left(T_{8}\right)$ by red blood cells. J. Geront. 1963, $18,151$. 